\title{
The Incompleteness of the Economy and Business: A Forceful Reminder
}

\author{
Paul H. Dembinski
}

Published online: 20 January 2012

(c) The Author(s) 2012. This article is published with open access at Springerlink.com

\begin{abstract}
Many different but related arguments developed in the Caritas in Veritate converge on one central, yet not clearly stated, conclusion or thesis: economic and business activities are 'incomplete'. This article will explore the above-mentioned 'incompleteness' thesis or argument from three different perspectives: the role, the practice and the purpose of economic and business activities in contemporary societies. In doing so, the paper will heavily draw on questions and, still not fully learned, lessons derived from the present financial and economic crisis. Caritas in Veritate provides an appealing moral framework in which many of these lessons take a deeper sense and a more comprehensive meaning. The notion of 'incompleteness' is applied here to economic and business theory and practice in the sense derived from Gödel's theorems. They state in terms of logical and mathematical demonstrations that no system of axiomatic statements can provide a proof of its own consistency. Such a proof requires the use of statements belonging to another (higher) level system. In the case of economics or business theory and practice these 'higher level' statements are value judgments. By stressing the importance of ethics and moral philosophy for daily life, Caritas in Veritate strongly reminds us that neither economy nor business are self-sufficient either in organisational and social, practical or moral terms.
\end{abstract}

Keywords Caritas in Veritate · Ethics · Exchange · Financial crisis · Gödel's Theorems · Incompleteness in

\footnotetext{
P. H. Dembinski $(\bowtie)$

University of Fribourg, Fribourg, Switzerland

e-mail: dembinski@obsfin.ch

P. H. Dembinski

Cardinal Wyszynski University, Warsaw, Poland
}

economics - Purpose of business - Relation - System of National Accounts (SNA) · Transaction

According to the too often-quoted phrase attributed to Milton Friedman, the 'purpose of business is business. ${ }^{1}$ However, by saying this, Friedman and his disciples suppose a shared understanding of what 'business' means in the two senses used in the aphorism: business as practice and business as purpose. If at one point there was an agreement in these questions, this is no longer the case as the present crisis has shaken many certitudes that went unquestioned for decades. In consequence, in this context the Friedmanite saying could well be nothing more than an elegant but void or even fallacious statement, or even a sophism. $^{2}$

The ongoing financial and economic crisis proves to be a very peculiar moment: unexpected, fearful, potentially lethal to our way of life, but paradoxically, until recently at least, it did not shake the way financial and economic activities are conducted or regulated. When the financial order was shaken to its roots, a number of wrongdoings were publicly confessed and promises were made both by private and public actors as to their future conduct. Looking back to the first pages of major daily newspapers during these months of fear, one has the impression that modern capitalism, tantalized by the crude colours in which the lightning of the crisis has put its functioning and

\footnotetext{
1 'Widely attributed to Friedman, and sometimes cited as being in his work Capitalism and Freedom (1962) this is also attributed to Alfred P. Sloan, with citation of a statement of 1964, but sometimes with attestations to his use of it as a motto as early as 1923.' Available at http://en.wikiquote.org/wiki/Milton_Friedman. Accessed 16 Sept 2011. See, among others, Davis (2005).

${ }^{2}$ Khurana and Gintis (2008).
} 
whereabouts, was examining its own practices without complacency whilst simultaneously reviewing its foundational values. In these moments of lucidity, practices were examined against values and judged in moral terms. As the storm calmed down, the existential fears disappeared. Consequently, 'real life' and self-preserving arguments of 'business as usual' resurfaced and regained progressively all the ground previously lost to idealistic ones. Today, little trace of these ambitious declarations and commitments is left either in public debate or in private practices. The gravity of the crisis and the seriousness of the flaws in dominant practices that appeared so clearly in the lightning of the storm are being forgotten or even denied, as if it was just a collective nightmare.

Caritas in Veritate (CV) was published in summer 2009, a few days before the Aquilla (Italy) G20 meeting. Speaking up when crisis fears were driving the level of systemic selfinsurance to its lowest level, gave the Pope a larger than usual audience and drew a lot of attention to the document. The encyclical did not address technical issues related to the financial crisis, but to the surprise of many, it put the crisis in a larger perspective by proposing a theological and eschatological reading of it. By doing so Caritas in Veritate-in line with the tradition of the social teaching of the Churchwas leaving to the addressees, people of good will, the task of choosing the most appropriate ways to bring their personal and social daily deeds and practices in harmony with the theological and eschatological requirements.

Whilst only seldom mentioned explicitly in the document, economic and business life is at the centre of papal concerns. Indeed, many different but related arguments developed in the encyclical converge on one central, yet not clearly stated, conclusion: contemporary economic and business practice and the related dominant theories are 'incomplete' at least from the Christian perspective. Consequently, they should neither be seen as autonomous nor self-sufficient. They need to be framed and supported on one side by the cultural and political concern for the common good and on the other by personal concern for fraternity, ethics and morality.

This article will explore the above-mentioned 'incompleteness' argument from three different perspectives: the role, the practice and the purpose of economic and business activities in contemporary societies. In doing so, it will draw heavily from questions and (still not fully learned) lessons derived from the present financial and economic crisis. Caritas in Veritate provides an appealing moral framework in which many of these lessons take a deeper sense and a more comprehensive meaning.

The notion of 'incompleteness' is used here in the sense derived from Gödel's well-known second theorem. This seminal theorem demonstrates in formal logical terms that a system of axioms can be proved as logically consistent only if it is incomplete. In other words, a proof of consistency of an axiomatic system requires the use of statements external to the system itself. When applied to economic and business practice or theory, the Gödel's theorem reminds us that those systems which pretend to provide an internal self-justification cannot but fail to do so and are, in fact, simply recursive. A final justification can only be derived from higher order statements that are external to the economic and business realm, namely moral philosophy or even theology. ${ }^{3}$ Keeping in mind Gödel's seminal contribution, the paper uses it to explore the logical underpinnings of the ways economic activity is justified, measured, assessed and practiced in the contemporary world.

\section{The Role of the Economy and Business in Society}

According to the well-known statement by Lionel Robbins, economics as knowledge, and, more broadly, economic activity, is about increasing the level of efficiency in the use of scarce resources to satisfy the unlimited needs of humanity. ${ }^{4}$ The achievement of the permanent increase in efficiency is guaranteed by the combination of two institutions with one rule of behaviour, namely the enterprise, the market and the so-called 'profit motive' or economic rationality.

In theory, when the system of perfectly interconnected markets is 'complete' (that is, when a market for every possible good or service exists), the inventiveness of business people eager to pocket profits drives society to the highest possible level of efficiency, but at the same time perfect competition prevents profits from growing beyond a median level achieved in all activities. This self-correcting mechanism keeps the idealized economy on the efficiency path. However, the abyss between theory and reality should not be neglected. In the real world markets are not complete, competition is not perfect and profits are far from negligible. Consequently, extreme caution should prevail in extrapolating to the real world any theory-based conclusion. Indeed, the temptation is enormous to take the promises of theory at their face value and transpose to the real world conclusions stemming from the idealized world of models.

Only if markets are complete in the above-mentioned sense, is limited profit an indication of efficiency in the use of resources. Indeed, the complete market hypothesis means that the market mechanism runs all dimensions, spheres, and issues of social life, leaving nothing outside of its scope and reach. Only under this extremely restrictive

\footnotetext{
${ }^{3}$ Gödel (1931), see also Weisstein (2011).

${ }^{4}$ Robbins (1932). 'Economics is the science which studies human behaviour as a relationship between given ends and scarce means which have alternative uses' (p. 16).
} 
hypothesis can the economic calculation be said to take into account all the costs and benefits (which are by definition expressed in monetary terms) without leaving anything of importance outside. In all other cases, one cannot exclude that in real world the economic activity generates, outside of the accounting perimeter, costs-and possibly benefits-usually called externalities, which are not taken into account in the calculation. In consequence, as long as the system of markets is incomplete, the result of any calculation in terms of monetary costs and benefits is undermined by the existence of externalities-which by definition have no price and no value tag. Thus, as long as the completeness hypothesis is not satisfied, every accounting profit or loss takes into account only costs and benefits which relate to the part of social life that is governed by market mechanism. Consequently, the pretension of economic calculus to lead society to enhanced efficiency has to be taken with great caution.

The financial crisis drew the public's attention to the enormous amounts of profits generated by banks and other financial institutions. In 2007, the US financial institutions were generating about $40 \%$ of corporate profits whilst contributing only $15 \%$ to the US GDP. ${ }^{5}$ If limited profits, according to the model, would indicate that efficiency is at its highest, extravagant profits say just the opposite. Other indications point in the same direction as they suggest that the level of strategic and financial interdependence in the global economy is growing and the level of competition remains low. Accordingly, the world economy could well be far from its optimal level of efficiency advocated by theory. ${ }^{6}$

Persistence of imperfect competition and of incomplete markets can lead to two opposite lines of action. According to the first-free market view-one should aim at extending the scope of markets to every dimension of social life, whilst for the other, meta-economic and political forces should limit the role of markets only to certain domains of social life. In the first case, as promised by theory, economic logic aspires to be the dominant principle governing society, and efficiency will remain its ultimate goal. In the latter case, market mechanism and economic logic are bound to be only one amongst other allocating mechanisms at work in society.

The discussion about the adequate extension and role of markets is not new. The question has also been, directly or indirectly, addressed in previous social encyclicals from Rerum Novarum to Centesimus Annus and also by many social thinkers and economists interested in Christian social thought or doctrine. ${ }^{7}$ Caritas in Veritate clearly states the

\footnotetext{
5 The Economist, 19 March 2008. Available at http://www.economist. com/node/10881318. Accessed 16 Sept 2011.

6 Dembinski and Fryzel (2010).

${ }^{7}$ Novak (1991), p. 112, Zieba (2000), Laurent (2007).
}

incompleteness of purely economic mechanisms by saying that "...the conviction that the economy must be autonomous, that it must be shielded from 'influences' of a moral character, has led man to abuse the economic process in a thoroughly destructive way. In the long term, these convictions have led to economic, social and political systems that trample upon personal and social freedom, and are therefore unable to deliver the justice that they promise" (CV 34). The Pope goes on to say that "[e]conomic activity cannot solve all social problems through the simple application of commercial logic. This needs to be directed towards the pursuit of the common good, for which the political community in particular must also take responsibility' (CV 36).

Sceptical about the capacity of market logic to run the whole of society, the encyclical acknowledges the importance of markets, provided the mechanism is not left alone. 'The Church has always held that economic action is not to be regarded as something opposed to society. ... Society does not have to protect itself from the market... (...) the market is the economic institution that permits encounter between persons' (CV 34). But later on, the encyclical qualifies as follows this statement: 'Without internal forms of solidarity and mutual trust, the market cannot completely fulfil its proper economic function' (CV 36).

\section{The Doubtful Relevance of SNA-Related Indicators}

Many interpretations and discussions took place to capture the precise meaning of the acknowledgment by the encyclical of the doctrinal incompleteness of the economic and business logic. This does not require further elaboration here. However, this doctrinal position-not new in Vatican documents-has important technical implications for the importance given to different measurements of economic activities in the overall assessment of the achievements of societies. This is especially the case with the set of concepts and measures rooted in the more than half a century old methodological framework of the System of National Accounts (SNA). Aggregates such as GNP and GDP, and the growth rates derived therefrom, are the most classical, best known and widely used set of economic measures and success indicators. Yet these tools carry with them a set of builtin assumptions and methodological limitations that are worth spelling out here when discussing the 'incompleteness thesis' of economics and business logic.

The relevance of SNA-related indicators for assessing the overall performance of societies has been criticized from five main angles, closely related to its 'incompleteness': the human development perspective, the happiness gap, the grey-economy, the ecological perspective and the uneven value perspective. 
In early 1990s, economists working with United Nations Development Programme started to devise ways to shift the development agenda away from SNA accounts to a more people-centred approach. In this framework, a Human Development Index (HDI) has been established. It combines GNP per capita with other indicators, such as access of children to education and life expectancy. Despite the fact that HDI levels present a rather high correlation with levels of GNP per capita, HDI has achieved its own legitimacy over the 20 years of its existence. ${ }^{8}$

The second line of critique of SNA is related to its empirically demonstrated inability to provide even an approximate indication of the level of happiness or well being of societies concerned. ${ }^{9}$

The third line of critique is summed up very clearly in the recent report authored by A. Sen and J. Stiglitz on flaws and limitations in the prevailing SNA. ${ }^{10}$ The issues raised by the group of eminent authors refer to limitations that prevent the SNA from covering all the fields it should. Consequently, the experts' effort aims at granting the possible maximal extension of the SNA framework so as to make it capture as much of social life as technically possible. Beyond technicalities, the authors do not see any other fundamental reason why the SNA coverage should not be complete and thus far extended beyond the scope presently governed by market mechanism.

The three mainly technical limitations of SNA on which the report focuses have been conceptually identified for a long time but are still present: (a) for administrative reasons, the SNA is unable to capture adequately all the ongoing economic activity such as grey or black economy, (b) the SNA does not encompass-mostly for technical reasons-quasi-economic activities performed outside of the market, such as household work and (c) the SNA does not properly capture all the costs related to the economic activity, especially the damage made to the environment which is, in accounting terms, a free good. On the basis of such a diagnosis, which in essence is far from new, most of the ongoing intellectual and technical efforts aim to make the SNA ever more all encompassing or more complete.

The fourth line of critique touches on the fundamental problem of how to know whether the accounting notion of 'value added' that stands at the centre of the SNA methodological framework also has a normative meaning, as the use of the word 'value' might suggest. In other terms, the question would be: 'Is any accounting value added positive or good?' In a strictly economic view, every sound activity from the business perspective is 'adding value' in the SNA sense. However, some of these activities may seem less

\footnotetext{
8 ul Haq (1995) and UNDP (2011).

${ }^{9}$ Frey and Stutzer (2002) and studies by Layard (2003).

${ }^{10}$ Presidency of the French Republic (2009).
}

valuable than others. An often-quoted example is a car repair after an accident. It adds value in the SNA sense, but usually results in a loss of the car's value for the owner. Gasoline spent in traffic jams by no means has either a positive effect on the economy, on the ecology or on society but, in accounting terms, it contributes to the increase of SNA based aggregates.

The point which this critique makes forcefully is to stress the fact that the accounting framework is unable by construction to distinguish between 'useful' value added, 'neutral' value added and 'not useful' or even deceptive value added. ${ }^{11}$ By taking the SNA figures at their face value, without any screening, one takes for granted that every accounting value added effectively adds value to society. In doing so, one implicitly, and erroneously, supports the claim of SNA framework to be 'complete' and more broadly to the view that the corresponding figures give a true and complete image of societal valuations and realities. In its ultimate conclusion, this argument converges with the one derived from the 'happiness paradox' discussed earlier.

Protagonists of debates around the financial crisis have, sometimes forcefully, asked what is the meaning or counterpart of the accounting value added (between 5 and $15 \%$ of GDP in OECD countries) by the financial sector? ${ }^{12}$ Every time an attempt is made to distinguish between 'valuable' and 'not so valuable' value added, the use of a value judgment is required. Such a judgment has, by definition, to come from the outside of the SNA framework. This fact further underlines its incompleteness. At its inception, in late 1930s, the SNA framework was not designed to be complete, its limits and limitations were widely recognized. Since then however, the SNA successes have been breeding the 'completeness' ambition, which is still prevalent today.

Finally, the fifth critique of the SNA-derived figures is probably the least researched for the time being but potentially the most devastating. The point to be made here is the following: as long as the SNA will not provide a 'complete' cover of all social and economic activities, its figures will remain not only incomplete, but also misleading, ideologically loaded and thus, simply wrong. An example will help to capture the argument: a meal taken by a group of five at home contributes to the GNP/GDP only for the amount of cost of its ingredients. The same meal taken at a restaurant would have a much greater contribution to GNP/GDP. Consequently, switching from homebased meals to restaurant meals will translate as economic growth both in terms of GDP and in terms of jobs. But is it really growth with its positive connotation? Or is it only

\footnotetext{
${ }^{11}$ For an excellent discussion of this problem, see Cobb et al. (1995).

12 Krippner (2005) and Dembinski (2009).
} 
expansion of the domain regulated by the business or market logic at the expense of another domain controlled by the logic of sharing? ${ }^{13}$

The example used here is not anecdotal. It explains one of the less studied aspects of the expansion of service activities. The growth of services in terms of jobs and value added, and the corresponding structural transformation, was the main engine of the economic growth that took place in OECD countries during the last decades. ${ }^{14}$ The argument presented here suggests that SNA figures are largely misleading. What they present as ex nihilo creation of value added, is - to a large extent-just a transfer of activities from non-market logic to the market logic. And here, an implicit value judgement carried along with the SNA framework comes into play as this transfer has been called 'growth' with its highly positive connotation. In other words, the hypothesis of a 'growth fallacy' has to be carefully investigated both from the quantitative and conceptual perspective.

Today, the dominant trend wants the SNA framework to be as complete as possible but, despite all the efforts, this goal has not yet been achieved. Most of the present SNA limitations would disappear if all social activity was conducted according to the market and business logic, and if humans were perfect homines oeconomici. But this is fortunately not the case. The critiques and limitations discussed here acknowledge in fact a double 'incompleteness' of SNA: on one side in terms of coverage, on the other in terms of incapacity to provide grounds for the ultimate value judgment. The discussion above allows us to derive three sets of not totally compatible positions in the debate. For the fatalists, the still prevalent hegemony of GDP/GNP figures has to be challenged by the use of other synthetic measures and indicators so as to provide an adequate assessment of social well-being. For the optimists, the SNA framework should be continuously expanded to make its measures and outputs more meaningful every day. And finally, for the realists, the scope, meaning and ambitions of the SNA should be explicitly contained so as to capture only the effective and valuable growth, i.e. all situations when only ex nihilo value creation takes place. This would leave aside 'apparent' growth (growth or activities derived from transfer of activities from one logic to another) outside of the SNA's scope and mandate.

This lengthy discussion of the SNA pretension to completeness has made more apparent the agenda hidden beyond accounting technicalities. In fact, this framework

\footnotetext{
13 Pigou (1932) in his seminal work 'Economics of Welfare' identified the following paradox as a serious but not a destructive shortcoming of the notion of 'national dividend': '... if a man marries his housekeeper or his cook, the national dividend is diminished'.

14 Maroto Sanchez (2010).
}

provides an implicit and partial intellectual justification for the continuous expansion of the role business and economic activities in contemporary societies. The arguments in favour of greater 'completeness' have proved in recent decades to be politically very seductive in most OECD countries despite sharp altermondialist critiques against the looming 'marchandisation' of the world. Caritas in Veritate insists that despite its seductive capacity, neither the 'completeness thesis' of economic life nor the claim of economic logic to be self-sufficient can be accepted on anthropological as well as on purely theological grounds. Whilst acknowledging the power and efficiency of the economic logic, the encyclical stresses also that they have to be oriented and guided from outside. 'This requires further and deeper reflection on the meaning of the economy and its goals, as well as a profound and far-sighted revision of the current model of development, so as to correct its dysfunctions and deviations' (CV 32). 'Development must include not just material growth but also spiritual growth' (CV 69). Or '(y)et it must be acknowledged that this same economic growth has been and continues to be weighed down by malfunctions and dramatic problems' (CV 21).

\section{The Practice of Business: From Efficiency to Fecundity}

After having shown how far reaching the implications of the incompleteness thesis are for the role that economic activities ought to play in society, the time has come to address its implications for the practice of business. The way business and economic activities are conducted stands at the centre of the Pope's concern. Indeed, the most striking paragraphs in Caritas in Veritate, deal with gratuitousness, and are of direct relevance to the actual practice of business.

'There is no free lunch'-this often repeated statement summarises the core principle of much of contemporary business thinking and practice. It is also the main principle of every 'serious' economics or management textbook. It means that there is no place left, and there should be no place left, for free gift and gratuity either in the business practice, in economic activity and even in economic thought.

Both economic practice and theory are based on the same premise: nothing is free; everything has to be paid or compensated for by an equivalent. From a business perspective a truly 'free lunch', with no expected future counter parties or advantages, means forgone income, whilst in macroeconomic terms, it means loss of efficiency. From this follows an important recommendation: if pockets of gifts and gratuity still exist, they should be eradicated in the name of increased income and macroeconomic gains in efficiency. As a consequence, gratuity is either business 
opportunity or waste and for both the reasons it should be substituted with a commercial transaction. By eradicating gratuity, humanity is supposed to head towards greater efficiency and closer to the ideal of 'complete markets' referred to in the previous paragraph.

In such a context, economic efficiency would be at its peak as the individual-perfectly selfish and, therefore, perfectly isolated-communicates with the rest of the world exclusively by means of prices and quantities. Thus, the intellectual building up of a society, not to say of a market civilisation, rests on a strong anthropological vision known by the name homo oeconomicus. In a world of homo oeconomicus, a free lunch is an absurdity. The anthropological cornerstone of contemporary economicist ideology has been laid down by Vilfredo Pareto in Lausanne, on the shores of Lake Geneva, where he lived at the beginning of the twentieth century. However, under Pareto's pen, homo oeconomicus was only an exercise in style. Over the last 20 years or so, the fundamentally selfish rationality of homo oeconomicus, totally devoid of any ethical concern, has become not only a general reference used in economic modelling but also the anthropological underlying present in business teaching and practice, especially in marketing. ${ }^{15}$ Although largely dominant, this paradigm is not totally hegemonic amongst economists. Some authors, such as Herbert Simon and Stefano Zamagni, to mention only two names out of a much longer list, argue that not only egoism but also altruism is compatible with economic thinking and theorizing. ${ }^{16}$

The practical relevance of this intellectual construct of economics as theory has been seriously brought into question by the current crisis. A world of complete markets, together with homo oeconomicus, suffices to establish an entirely and exclusively economic ideal of civilisation. In such a world, the clash of selfish individuals, put into competition by the market, is sufficient to solve all problems and all conflicts through exchange transactions (see below). Such a state of affairs corresponds to the ideal of what may be called 'economic fundamentalism' which could — if it has not happened already_-degenerate into an ideology.

Caritas in Veritate refutes point by point both the economistic ideology and the resulting business practice. 'There ought to be (some) free lunches,' the Pope seems to say. This is so because human nature blossoms and reaches its fulfilment in generosity and in generous relations with

\footnotetext{
15 Demeulenaere (1996) and Dembinski (2005).

16 When discussing the current use made of utility theory, Herbert Simon reminds us that it is compatible with an altruistic anthropology but also acknowledges that its use has been distorted: 'that economic actors desire only economic gain is a far stronger assumption that they maximize utility. It is also empirically false' (p. 158). Simon (1993); on this topic, see also Zamagni (1995).
}

others. The Catholic Church offers a reading of human nature diametrically opposite to that of homo oeconomicus. Charity (Caritas) can not have another foundation or justification than that of the truth (Veritas) of the human nature. The encyclical clearly spells out the link between the two, '(t)ruth opens and unites our minds in the logos of love' (CV 4). Nowadays, business practice and economic thought tend rather to pose as centres of social and individual life. Taking the opposite view, Benedict XVI (2009) emphasises their incompleteness. Business and financial transactions are, at best, means, whilst what is truly at stake concerns the ends. Economic and business activities are there to serve human destiny rather than preside over it. The encyclical states that if the market is governed solely by the principle of the equivalence in value of exchanged goods, it cannot produce the social cohesion that it requires in order to function well. Without internal forms of solidarity and mutual trust, the market cannot completely fulfil its proper economic function' (CV 35).

Although the encyclical recognises explicitly the importance of the equivalent exchanges, of contracts, of profit and of the institutions that are governing them, i.e. the market and the enterprise, it calls to see them as means and to discover their proper meaning in the light of proper goals. These means are necessary, but not sufficient to allow each human being and all people to fulfil their vocation of integral development. It is not a question of legislating or of acting through macropolitical regulations, which hardly succeed, as it is in guaranteeing a minimum of justice, but of reconfiguring in depth the practice and behaviour of economic agents. 'The importance of this goal is such as to demand our openness to understand it in depth and to mobilize ourselves at the level of the 'heart', so as to ensure that current economic and social processes evolve towards fully human outcomes' (CV 20).

At the heart of the papal diagnosis lays the non- or illdevelopment of contemporary humanity, a situation that does not come down to the material dimension only and that is not confined to the so-called developing countries. The current crisis, then, is 'an opportunity for discernment, in which to shape a new vision for the future.' The encyclical insists on a necessary double renewal to come out of the crisis. It is necessary to start at the intellectual level where the need for a 'new humanist synthesis' is striking, and follow with practical action, where new business models, practices and structures are to be experimented with and put into action.

This double renewal demands that human truth should never be lost from sight in such abstractions as structure, technique, progress and growth. Profit and market can never overwhelm human beings in their individuality and their uniqueness. How are we to articulate the generous aspiration to this 'new humanism' in day-to-day action? In 
the encyclical there are no recipes or magic wands, there are no technical and impersonal "it's just a question of 'one should' or 'one must'". The only practicable path suggested by Benedict XVI is that we are all to act or, more realistically, that each person starts acting without waiting for the others. By doing what? And here comes the revolutionary recommendations: by putting some giving and generosity into the heart of business practice (not aside of it), which means by going beyond the strict (and in fact sterile) equivalent exchange to write a surplus into it, a dimension of giving. The encyclical says indeed that ' $(t)$ he great challenge before us, accentuated by the problems of development in this global era and made even more urgent by the economic and financial crisis, is to demonstrate, in thinking and behaviour... that in commercial relationships the principle of gratuitousness and the logic of gift as an expression of fraternity can and must find their place within normal economic activity' (CV 36). These words are an invitation to business practitioners to acknowledge and bypass the highly seductive but erroneous vision of equivalence and of completeness at the heart of the currently prevailing 'no free lunch' paradigm. This is a call to part ways with the corresponding economistic ideology.

The current prevalence of the equivalent transactions in the business world derives from their key technical features that make them easy to manage. The first characteristic of transactions is their impersonality. In transactions, what matters are the goods exchanged, not the persons or actors who exchange them. Consequently, the identity of actors does not and should not have any impact on the price paid or on the quality of the purchased unit of good. Each unit is supposed by the theory to be strictly identical to all the others. This may be true in depersonalised industrial production, but is more difficult to be achieved in services. That is the reason why sophisticated marketing tries to 'personalize' the transaction. This is, however, only a mere instrumental customisation dictated by yield-management techniques, rather than true personalisation that would require taking into account the genuine person of the other.

A second important characteristic of transactions is their instantaneity. A transaction is equilibrated at the moment it takes place, there is no future to it, and there is no past, only the instant when the equivalence has been established by agreement of parties. A transaction is instantaneous and therefore static by design.

A third characteristic is the completeness or equivalence of transactions in line with the 'no free lunch' principle. Every dimension of the exchanged goods or services is taken account of in the price formation; nothing is left for free or unpaid for.

A fourth characteristic is the fact that an impersonal transaction will only take place in an environment in which the necessary level of trust has been provided by means external to the transaction itself. Auditors, solicitors, lawyers, experts, insurers, brokers, etc. embody the rule of law, which in the last analysis provides trust necessary to allow impersonal actors to exchange and trade on more or less organized markets.

Finally, the fifth and last characteristic of transaction is its instrumental nature. Impersonal buying or selling is a mean used by each of the parties to achieve a goal that lies, by definition, outside of the transaction itself. The transaction will provide cash to the seller that she will be able to use when buying goods and services, whilst the buyer will use the purchased goods to satisfy a more or less urgent need. Consequently, parties aspire only to an efficient closing of the transaction.

Due to these characteristics, transactions may appear as self-contained and independent units easy to quantify, to assemble, sort or categorise. As such they are easy to manage by impersonal and highly technical procedures used in corporations and taught in modern business schools. ${ }^{17}$ On a macroeconomic level, the world made of transactions appears in the categories of economic analysis as efficient. All this being said, Caritas in Veritate is much less enthusiastic about the prevalence of transactions than economist view and business practice would expect. The main reason for this discomfort is the moral incompleteness of transactions, which are unable to provide 'heart' to efficiency. They are unable by themselves to turn efficiency into fraternity, as they are unable to turn growth into integral development. The main reason for this is the inability of transactions to acknowledge the uniqueness of the other, to see the counter party to the transaction as a person. The encyclical says, '[e]conomic, social and political development, if it is to be authentically human, needs to make room for the principle of gratuitousness as an expression of fraternity' (CV 34). Previously, the following distinction between neighbours and brothers has been made: 'As society becomes ever more globalised, it makes us neighbours but does not make us brothers. Reason, by itself, is capable of grasping the equality between men and of giving stability to their civic coexistence, but it cannot establish fraternity' (CV 19).

It has been argued at length that the rapid growth of the number of financial transactions during the last quarter of century was one of the causes of the crisis. It has also been argued that for a long time a shift was taking place in banking business models from relation-based business models to transactions based-ones. ${ }^{18}$ Today the quantitative supremacy of transactions over relations is very clear in the financial arena. But in fact it also affected other industries and most of received business practices. During

\footnotetext{
${ }^{17}$ Mintzberg (2004).

18 Dembinski (2009) and Meeerschwam (1987).
} 
the last quarter of the twentieth century western societies moved a long way from Tönnies's Gemeinschaft to Gesellschaft. In this process, the fecundity of relations as a mode of interaction has been sacrificed to the promises of efficiency carried by a transaction-based society.

As the encyclical invites people of good will to rediscover the 'category of relation', it provides a unique opportunity to oppose the two notions, transaction and relation, and contrast their features along the lines proposed above. If a transaction is anonymous and impersonal, quite the opposite is true for relations. Only when parties know each other in their peculiarities, might they enter a relationship. This is, for instance, true in a debt relation which leaves room for the mutual adaptation and recognition of peculiarities and singularities of each of the parties. If transactions are instantaneous, relations have by definition a duration: some are everlasting, others are short, but all extend beyond the instant. A relation is, therefore, inscribed in time and as such has a history, and in most cases, a future. Consequently, relations have a built in dynamic, as opposed to the instantaneous and static nature of transactions. If transactions are, or at least pretend to be, technically complete because they are built on equivalence in an economic sense, relations, by definition, are a succession of unbalanced moments. Like walking, a relation is a succession of disequilibria that feed and counter-balance each other. This non-equivalence characteristic of relations provides room for gratuitousness and gift that can develop into reciprocity (which is not identical with equivalence). For instance, trust is one of the most important gifts that a party to a relation - any relation including a business onecan give to the other party. Once introduced into a relational framework, trust can grow (or disappear) as the seed of a fruit that will blossom and mature in the next stages of the relation. Unpredictable as to its future, a relation is potentially the locus of fecundity whilst transactions do not leave any room for it. Many business examples show that joint projects and cooperation often lead to totally unexpected fruits.

As said before, transactions require trust to be provided by the environment in which they take place. Indeed, the rule of law, the judiciary institutions, accounting rules, procedures and, in some cases, also raking agencies, are supposed to provide external trust necessary for smooth, impersonal and anonymous transactions. In the case of relations, the situation is different: trust-or distrustdevelops internally. Parties trust each other because they know their respective individual peculiarities. Consequently, when developed into networks, relations can contribute to an increased level of trust in society. The famous saying of London bankers 'my word is my bond' does not mean anything outside of a club or network of mutually trusting gentlemen. This, however, should not obscure the fact that mafia and other criminal networks are also built on mutual trust (and sometimes fear).

It has been shown that in transactions the other party is instrumental. This is only to some extent true in relations where the other has a face, an identity and a time-span. Even in a business environment where relations are tools for conducting operations, seldom are they only instrumental. If this is the case, they will fail because of not having achieved the minimal level of trust required for a more forceful development. More and more often smaller enterprises complain about the fact that their larger business partners have totally lost the sense of inter-personal relations and run business on a purely contractual basis.

By contrasting relations with transactions, their potential clearly appears. Transactions, by their commitment to instantaneous efficiency, deliver immediately everything that can be harvested at once. On the opposite side, relations balance the fruits of past efforts with the seeds for future results. Looking from a strictly business perspective, both the transactions and relations are useful and complement each other to a large extent. The crisis has shown, however, that the preference for transactions, one aspect of which is short-termism, has driven our economies into very dangerous waters. The best example in this context is the so-called 'originate and distribute' strategy of financial institutions active in the sub-prime. ${ }^{19}$ This strategy attracted much attention after the crisis and may have been one of the triggering factors of the crisis. In this business model, the mortgage financial relationship was initiated only with the purpose to be sold on to another financial institution. In this example, the relation was instrumentalized for the needs of a subsequent transaction. ${ }^{20}$

The call of Caritas in Veritate to redesign business practice comes at a time when the business community is rediscovering the need for trusting relationships but for less theological reasons. The reason lies in security and proper risk management. The convergence of these two concerns provides a window of opportunity for a profound change in practice but also in the way future business people are trained. Thinking and acting more long term could open up the minds of decision makers to distil some graciousness in the hard world of business which may lead them to recognize the face of the other-using Levinas's imagesbehind the cells of their Excel spreadsheets.

\footnotetext{
${ }^{19}$ Bank of International Settlements started warning about the dangers of this strategy as soon as 2006 and 2007-see the corresponding BIS's Annual Reports.

${ }^{20}$ Frankel (2002).
} 


\section{The Purpose of Business-Serving the Person}

As mentioned above, according to the widely quoted, but fortunately not always accepted, Friedmanite saying, the practice of business is business's only purpose. More precisely, and in line with today's dominant 'shareholder view' of the corporation, this means that return on capital should be the main purpose of business. The incompleteness thesis (or argument) challenges forcefully this extremely narrow view of the purpose of economic and business activities. The encyclical strongly qualifies the currently undisputed 'profit motive': '(p)rofit is useful if it serves as a means towards an end that provides a sense both of how to produce it and how to make good use of it. Once profit becomes the exclusive goal ... it risks destroying wealth and creating poverty' (CV 21). These words stand in sharp contrast to the emblematic response of Gordon Gekko, the hero of the film Wall Street (1987). When asked about how much he wanted to earn, his answer was simply 'more'.

Over the past years much has been written about the role of the 'greed factor' in the making of the recent crisis. ${ }^{21}$ Legal and mechanical checks and balances have been discussed and devised including limitations on top executive remunerations and bonuses. G-20 was supposed to propose a global measure on these issues-but progress has been more than limited. This being said, such measures did not address the issue of purpose in its essential meaning. According to the still prevailing dominant view, inherited from Mandeville, private vices-thanks to the mysterious and almost divine work of the invisible hand-are transformed into public virtues. ${ }^{22}$ The logical strength of this argument has seduced generations of social philosophers and business leaders as it makes senseless any discussion about the 'true' purpose of business. On the contrary, the encyclical, in line with previous papal teaching, even though it acknowledges the importance of profit as success indicator, stresses that it needs to be at the service of a higher purpose.

The main qualification here is that profit as such does not tell anything either about the conditions in which it has been generated or used. No moral judgment on profits can be formulated without clarity on these two points. Unlike the contemporary 'new philanthropy', which underlines the generosity of those that made fortunes when they distribute them, for the Christian, the ways in which profit has been generated is probably even more important than its use. Indeed, from a management perspective, profit may-in some cases-result from a lack of commutative justice in the relations between the enterprise and its main

\footnotetext{
21 Among many books and articles, Augar (2005), Partenoy (2003), or Anne (2010).

${ }^{22}$ Foley (2006).
}

stakeholders. It may well happen that the enterprise takes advantage of its market power to enforce prices or wages that are unjust. This may happen without any violation of existing positive legislation, but only by violating the natural duty of justice and prudence. ${ }^{23}$

This discussion shows that if the purpose of business is limited to 'profit', it is set to remain incomplete. It misses the ultimate purpose of any human economic activity: 'Man is the source, the focus and the aim of all economic and social life'. ${ }^{24}$ This reminder has far reaching consequences for the business world; man is to be served, not to be taken advantage of. Thus, the purpose of business is to help human development, and not to enslave him to services and products he does not really need. Neuro-marketing today is well advanced in the use of sub-conscious selling techniques, brand management and advertising campaigns that 'target' (in the proper sense) segments of the market often made up of the most vulnerable, as in the case with the sub-prime mortgages. ${ }^{25}$ All these techniques aim at generating profits, at building up the shareholder value of companies. But do they serve men and women?

The encyclical also reminds us that the 'subsidiarity principle' is above all a moral, and not merely a management, principle (CV 57). Although subsidiarity is often referred to in matters of political, constitutional and social organisation, its moral underpinnings are seldom discussed in the context of economic and business activities where it is seen more as a management tool of decentralisation aiming at increasing the overall efficiency of the organisation. If taken earnestly and applied to economic life, the moral dimension of subsidiarity could well suggest that economic and business activities have to preserve and respect the autonomy of the clients with regard to goods and services that may put them into dependence. This reminds us once again that the conditions in which profit has been generated are at least as important as the amount of profit itself.

If businesses were careful at producing only goods and services that ennoble their clients and help them in their integral development, then only 'good value added' would be produced in the economy. Consequently, one of the limitations of the SNA discussed earlier would disappear.

\footnotetext{
${ }^{23}$ When analysing the current financial crisis, the Bank of International Settlements states the following in its Annual Report (2009): '...these weaknesses allowed the entire financial industry to book profits too early, too easily and without proper risk adjustment' (p. 7).

${ }^{24}$ Caritas in Veritate, 27, quoting Second Vatican Ecumenical Council, Pastoral Constitution on the Church in the Modern World Gaudium et Spes, 63.

25 Twitchell (1998).
} 


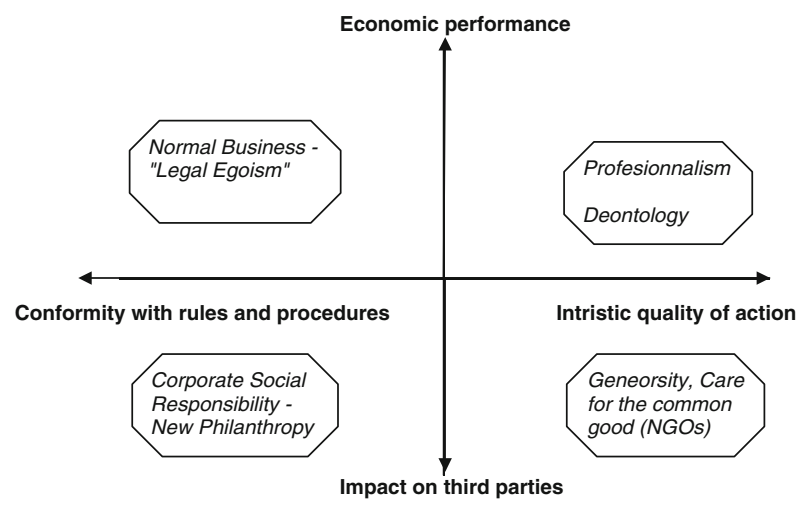

Fig. 1 Ethics in business: four dimensions that help give sense and meaning to any business and economic decision

\section{Beyond Incompleteness-Towards a Unique Decision Framework}

Figure 1 below proposes a frame of reference that may be helpful for checking the meaning and sense of business decisions or actions. This framework is the cornerstone of an assessment methodology currently being developed by the Observatoire de la Finance, called 'Mind the (ethical) gap'. ${ }^{26}$ It suggests that every business or professional decision has at least four dimensions and that each of these dimensions stems from a specific paradigm and should be considered together with the other dimensions before a final decision is reached. When applied to specific situations or decisions, this analytical framework could assist in searching for options and alternatives, as it shows that more often than not, in real life, tension may occur between the legal deeds, the profit motive, the care of the intrinsic quality of action, and the external impact of any decision.

This framework has four dimensions, each of which contributes to giving a moral compass to any business decision: (a) in the North: contribution to economic performance, (b) in the East: the intrinsic quality of the action, the professional 'doing well', (c) in the South: the quality of impact the decision has on third parties, on those that are not involved in the decision making process and will be confronted with its consequences, (d) in the West: the degree of conformity with legal rules and internal procedures of the enterprise.

In a 'complete' business world, corresponding to the one depicted by the dominant economic theory, only the N-W part of the diagram matters, the other portions are irrelevant. On the opposite, in an environment where gratuitousness prevails, S-E portion plays a prominent role.

By reminding us that the four dimensions give meaning simultaneously to any decision, this assessment framework offers a possibility to escape the golden prison of the

$\overline{26}$ Available at www.obsfin.ch. Accessed 16 Sept 2011. completeness dogma. Indeed, the only way for new humanism to progress in the business community is to remind us of the meta-economic meaning of any economic or business activity.

\section{Conclusions}

The crisis has increased the interest for 'ethics' in the business world, at least in some of its circles. In parallel, on the political level, in the aftermath of the crisis, a broader call to 'moralise capitalism' has been issued by the French President Nicolas Sarkozy in January 2009. ${ }^{27}$ Even if these words remain, for the time being, without clear content, their use shows that many share the feeling that the 'profit motive' is an incomplete and even dangerously reductive description of the true purpose of business.

Ethics specialists also seem to be divided on the issue of purpose. Two main approaches can be distinguished: the dominant 'Business Ethics' view closer to professional deontology (i.e. obligations agreed within a profession and related to its role in society) and the 'Ethics in Business' which acknowledges that the source of ethics is transcendent to the realm of business and professional life. The two best-known traditions of 'Ethics in Business' are virtue ethics and the Kantian categorical imperative approach.

For the currently dominant 'Business Ethics' view, deontology seen as a set of accepted professional codes of conduct will guarantee and preserve the good functioning of the business community or of the market. This approach to ethics takes business activity and its logic as a given. For the 'Ethics in Business' approach, business is a field in which more general ethical principles have to be applied. This allows for a constant questioning of business logic itself and requires consequently the identification of the underlying general ethical questions behind the peculiarities of every business situation or action. ${ }^{28}$ Only this approach, which refers to 'higher level' statements, is compatible with the incompleteness view as it refers to values and virtues that have a universal meaning, not limited to the business sphere and not derived from it. For the 'Ethics in Business' approach, the ethical obligations are exogenous and transcendent to the field of business whilst they are to a large extent endogenous to it for the 'Business Ethics' view. ${ }^{29}$

\footnotetext{
27 'La crise du capitalisme financier n'appelle pas à la destruction du capitalisme, qui serait une catastrophe, mais à sa moralisation' said President Sarkozy on the 8 Jan 2009. Available at http://www.elysee. $\mathrm{fr} /$ president/les-actualites/discours/2009/colloque-nouveau-mondenouveau-capitalisme.6846.html. Accessed 16 Sept 2011.

28 Mele (2009).

${ }^{29}$ Ossipow (2010).
} 
This article has shown that one of the ultimate points the last encyclical makes is to stress the unbridgeable incompleteness of business and economic activities. Such a conclusion may be destabilizing to many who might have thought or even taken for granted, as they follow the still dominant paradigm in business, that the economic and business life was morally autonomous. This article has argued, using Gödel's theorem, that the claim for moral autonomy is logically inconsistent as neither business practice nor economic activity can provide a self-justification without referring to 'higher level' statements. This means that economic activity and business practice, in any case, rely on a moral judgment either made implicitly or explicitly. By making the 'incompleteness' point clear, Caritas in Veritate encourages all of us to spell out and critically assess the content of the implicit 'higher level' statements that we use to confront our 'business as usual' worldviews. To Catholics, and more broadly to Christians, the encyclical provides an in-depth moral and theological discussion of the 'higher statements' relevant to their worldview. In doing so, the encyclical provides a powerful pedagogical instrument for Christians and contributes greatly to laying the groundwork for dialogue on these issues between Christians and non-Christians.

This being said, those who want to take the incompleteness argument seriously and want to act consequently, will have to change their way of thinking and acting in their professional life. It will require from all concerned, business and political decision makers as well as civil servants and middle management, to permanently question and assess the meaning of their activities in the perspective of the ultimate finality of every human deed: the fostering of the human fraternity.

Acknowledgments The author is grateful for comments and suggestions to many friends and colleagues-including the two anonymous reviewers-who have been kind enough to discuss previous versions and arguments of this article: Rafael Alvira, Don Patrick de Laubier, Lubomir Mlčoch, Françoise and François-Marie Monnet, Etienne Perrot S.J., Manfred Spieker, Domingo Sugranyes, and the Right Rev. Justin Welby.

Open Access This article is distributed under the terms of the Creative Commons Attribution Noncommercial License which permits any noncommercial use, distribution, and reproduction in any medium, provided the original author(s) and source are credited.

\section{References}

Anne, T. (2010). Die Ger war Grenzlos. Berlin: Ullstien.

Augar, P. (2005). Merchants of greed, the greed merchants: How the investment banks played the free market game. New York: Penguin Books.
Bank of International Settlements, Annual Reports. (2009). Available at www.bis.org. Accessed 12 March 2011.

Benedict XVIth. (2009). Caritas in Veritate, Vatican City. http://www. vatican.va/holy_father/benedict_xvi/encyclicals/documents/hf_ benxvi_enc_20090629_caritas-in-veritate_en.html. Accessed July 2009.

Cobb, C., Halstead, T., \& Rowe, J. (1995). If the GDP is up, why is America down? Atlantic Monthly, October, 59-68.

Davis, I., (2005). What is the business of business? McKinsey Quarterly, August 2005, 105-113.

Dembinski, P. (2005). From Homo oeconomicus to homo ethicus. Finance \& the Common Good, 22(2), 3-7.

Dembinski, P. (2009). Servant or deceiver? Financialization at the crossroads (p. 200). London: Palgrave.

Dembinski, P., \& Fryzel, B. (Eds.). (2010). The role of large enterprises in democracy and society. London: Palgrave.

Demeulenaere, P. (1996). Homo oeconomicus. Paris: Presses universitaires de France.

Foley, D. (2006). Adam's fallacy. A guide to economic theology. Boston: Harvard University Press.

Frankel, T. (2002). Honour and trust. American business culture at the crossroads. Oxford: Oxford University Press.

French Republic, Presidency. Report by the Commission on the Measurement of Economic Performance and Social Progress. (2009), p. 300.

Frey, B., \& Stutzer, A. (2002). What can economists learn from happiness research? Journal of Economic Literature, 40(2), $402-443$.

Gödel, K. (1931). Über Formal Unentscheidbare Sätze der Principia Mathematica und Verwandter Systeme. Monatshefte für Mathematik und Physik, 38, 173-198.

Khurana, R., \& Gintis, H. (2008) What is the purpose of business? BizEd, Jan/Feb, 55-56.

Krippner, G. (2005). Thie financialization of the American economy. Socio-economic Review, 3(2), 173-208.

Laurent, B. (2007). Eseignement Social de l'Eglise et l'économie de marché. Paris: Parole et Silence.

Layard, R. Happiness: Have social sciences a clue?_Lionel Robbins Memorial Lectures 2002/2003 delivered at the London School of Economics. http://cep.lse.ac.uk/events/lectures/layard/RL030303.pdf. Accessed Jan 2010.

Maroto Sanchez, A. (2010). Growth and productivity in the service sector: The state of the art. IAES Working Paper Series 7/2010. Instituto de Análisis Económico y Social, Alcalá de Henares. Available at http://www.iaes.es/publicaciones/DT_07_10_ing.pdf. Accessed Sept 2011.

Meeerschwam, D. (1987). Breaking relationships: The advent of price banking in the US. In S. Hayes (Ed.), Wall street and regulations (pp. 63-97). Boston: Harvard Business School Press.

Mele, D. (2009). Business ethics in action: Seeking Human Excellence in Organisations. New York: Macmillan.

Mintzberg, H. (2004). Managers not MBAs. London: Prentice Hall.

Novak, M. (1991). The spirit of democratic capitalism. London: IEA Health Welfare Unit.

Ossipow, W. (2010). Deux pistes pour penser les relations entre éthique et finance. Finance \& Bien Commun, 36, 125-135.

Partenoy, F. (2003). Infectious greed. New York: Times Books.

Pigou, A. (1932). Economics of welfare (first published in 1920). London: Macmillan. Available at http://www.econlib.org/library/ NPDBooks/Pigou/pgEW.html. Retrieved 30 May 2011.

Robbins, L. (1932). An essay on the nature and significance of economic science. London: Macmillan.

Simon, H. (1993). Altruism and economics. American Economic Review, 83(2), 156-161.

Twitchell, J. (1998). Lead us into temptation. The triumph of American materialism. New York: Columbia University Press. 
ul Haq, M. (1995). Reflections on human development. New York: Oxford University Press.

UNDP. (2011). Human Development Report, annual publication. Available at www.hdr.undp.org. Accessed Jan 2012.

Weisstein, E. W. (2011). Gödel's second incompleteness theorem, from mathworld-a wolfram web resource. Available at http:// mathworld.wolfram.com/GoedelsSecondIncompletenessTheorem. html. Accessed 16 Sept 2011.
Zamagni, S. (Ed.). (1995). The economics of altruism. London: Edward Elgar.

Zieba, M. (2000). Les Papes et le Capitalisme (Saint Augustin, Saint Maurice). 